\title{
Study of the mechanical behaviour of rockfill subjected to creep, for different values of relative humidity, using the discrete element method
}

\author{
João Manso $^{1}$, João Marcelino ${ }^{1}$ and Laura Caldeira ${ }^{1}$ \\ ${ }^{1}$ National Laboratory of Civil Engineering, Geotechnical Department, Lisbon, Portugal
}

\section{Introduction}

The demand for energy across the world has been constantly rising since the last century and hydroelectric dams became a key element in every country. It is necessary to develop management strategies to preserve these energy facilities. It is an important aspect to provide scientific data and information on these facilities, in order to preserve the original function as long as possible. A type of hydroelectric dams are rockfill dams. One of the main issues in rockfill embankments have are severe collapse settlements that can occur due to wetting and, in some extent, due to seasonal air moisture variations. These settlements can cause loss of serviceability and imply expenses to recover operation. This paper focus in the assessment of the the compressibility of rockfill material, which may be affected by severe seasonal wetting and drying cycles. In an relatively novel approach this analysis was performed using the discrete element method, considering different values of relative humidity. Particles are modelled as breakable agglomerates of clumps with bond strengths, whose parameters are calibrated from experimental tests. Results reasonably mimic the material macro-response, since particle movements and interactions were determined using DEM. The numerical results were analysed on macro- and micro-scales allowing to study the influence of stress and relative humidity on the compressibility of rockfill materials.

\section{Numerical Simulations}

In this study was developed a clumped model, that allows for grain breakage, in order to investigate the effect of relative humidity on the macro- and micro-behaviour of rockfill along different stress paths. Similar technique was adopted by previous researchers, e.g., Cheng et al. (2003) and Kwok and Bolton (2013). The discrete element code YADE was used for this investigation. Each rockfill particle was created by bonding 3 clumps, constituted by 13 spheres in a regular assembly of hexagonal close packing (Figure 1). They could break if the strength of the bonds connecting the clumps was exceeded and their shape would change due to the broken fragments that remained in the simulation.

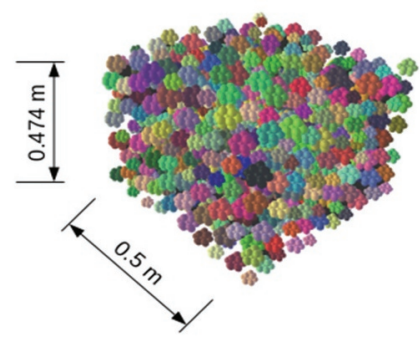

Fig. 1: DEM cubic specimen

The same methodology was applied to carry single particle crushing tests on 30 rockfill particles and the survival probability curve was found to match the Weibull distribution. The numerical simulation started by creating an initial set of exo-spheres placed randomly, without overlaps. After that, they were cycled until equilibrium was reached, reducing unwanted gaps. Table 1 presents the characteristics of the numerical specimen. The shear stiffness and the friction coefficient were reduced to zero, while the lateral wall stiffness was reduced ten times ( 5 . $107 \mathrm{~N} / \mathrm{m}$ ) and the initial normal stiffness was increased 100 -fold $(5 \cdot 1010 \mathrm{~N} / \mathrm{m})$, during the process of preparing the specimen. Then, each exo sphere was replaced by a regular assembly of elementary spheres in hexagonal close packing, where the radius of the spheres within this assembly was $20 \%$ of the original exo sphere. Clumps were created until all particles were clumped. The new specimen was cycled again until equilibrium was reached. In order to reduce the possibility of breaking the bonds during the preparation of the specimen, their strengths were initially set very high $(109 \mathrm{~Pa})$ and the shear and normal stiffness were set to $9 \cdot 106 \mathrm{~N} / \mathrm{m}$. This objective was achieved and no bonds broke during the specimen preparation process, after introducing the clumps, for an equilibrium stress of $5 \mathrm{kPa}$. Before starting the test, bond strengths were fixed to their final value $(103 \mathrm{MPa})$, the

\footnotetext{
* Corresponding author: jmanso@,1nec.pt
} 
Table 1: Characteristics adopted to simulate the oedometer specimen

\begin{tabular}{|c|c|c|c|c|}
\hline \multirow{2}{*}{$\begin{array}{l}\text { Input parameter } \\
\text { Height }[\mathrm{m}]\end{array}$} & \multirow{2}{*}{$\begin{array}{c}\begin{array}{c}\text { Numerical } \\
\text { value }\end{array} \\
0.474\end{array}$} & \multirow{2}{*}{$\begin{array}{l}\text { Input parameter } \\
\text { Relative humidity [\%] }\end{array}$} & \multicolumn{2}{|c|}{ Numerical value } \\
\hline & & & 50 & 100 \\
\hline Width [m] & 0.500 & $\begin{array}{l}\text { Normal and shear bond stiffness (parallel bonds) } \\
{[\mathrm{N} / \mathrm{m}]}\end{array}$ & $0.95 \cdot 10^{8}$ & $1.1 \cdot 10^{8}$ \\
\hline $\mathrm{D}_{\min }, \mathrm{D}_{\max }[\mathrm{mm}]$ & $19.1,38.1$ & $\begin{array}{l}\text { Normal and shear bond strength (parallel bonds) } \\
{[\mathrm{MPa}][\mathrm{mm}]}\end{array}$ & \multicolumn{2}{|c|}{$1 \cdot 10^{3}$} \\
\hline Clump size $[\mathrm{mm}]$ & $10.0 \pm 0.2$ & Radius multiplier (parallel bonds) & \multicolumn{2}{|c|}{0.5} \\
\hline Density $\left[\mathrm{kg} / \mathrm{m}^{3}\right]$ & 2052 & Normal and shear bond stiffness $[\mathrm{N} / \mathrm{m}]$ & \multicolumn{2}{|c|}{$2 \cdot 10^{10}$} \\
\hline $\begin{array}{l}\text { Normal and wall stiffness } \\
{[\mathrm{N} / \mathrm{m}]}\end{array}$ & $5 \cdot 10^{8}$ & Friction coefficient & \multicolumn{2}{|c|}{0.5} \\
\hline
\end{tabular}

contact shear and normal stiffness were set to $2 \cdot 1010$ $\mathrm{N} / \mathrm{m}$ and the friction coefficient was set to 0.5 , corresponding to a contact friction angle of $26.5^{\circ}$. The differences of behaviour, regarding different relative humidity conditions, were matched by setting different values for normal and shear bond stiffness of parallel bonds (Table 2). Creep was studied in each loading step of the tests. The loading was applied in increments of 100 $\mathrm{kPa}$, up to $1 \mathrm{MPa}$, using steps of 24 hours.

\section{Results}

Oedometric compression curves between the experimental test and the DEM simulation with a platen speed of $0.01 \mathrm{~m} / \mathrm{s}$ are compared in Figure 2, for each relative humidity condition. Although compressibility was clearly different, for both conditions, simulations were capable of capturing the essential of material behaviour. During loading, both shapes are similar and the DEM simulations capture the transition from particle rearrangement, due to elastic compression, into what may be described as clastic compression. Clastic yielding happens when the applied stress causes the onset of particle crushing, assuming that the onset of particle breakage leads to the bending of the normal compression line, causing the rapid increase of the material compressibility index. During unloading, the simulated rockfill also showed good similarities with the laboratory test. These results show that the presented simulation approach was generally capable of describing the oedometer compression response.

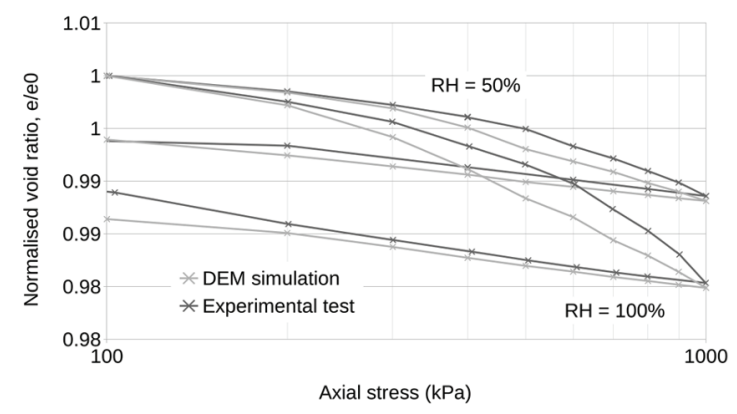

Fig. 2: Oedometric compression curves, normalised voids ratio against axial stress for relative humidities of 50 and $100 \%$

\section{References}

1. Cheng Y. P., Nakata Y., and Bolton M. D. (2003). "Discrete element simulation of crushable soil." Geotechnique; 53 (7), 633-41.

2. Kwok C. Y., Bolton M. D. (2013). "DEM simulations of soil creep due to particle crushing." Geotechnique; 63 (16), 1365-76. 